\title{
Malnutrition: a frequent misdiagnosis for hemodialysis patients
}

\author{
William E. Mitch \\ Nephrology Division, Department of Medicine, University of Texas, Galveston, Galveston, Texas, USA \\ J. Clin. Invest. 110:437-439 (2002). doi:10.1172/JCI200216494.
}

Precision in the use of words is necessary in any discipline, and this holds true for physicians and investigators dealing with patients who have chronic kidney disease. Specifically, malnutrition is often used to describe a group of abnormalities fatigue, loss of body weight with muscle mass being replaced by fatty tissue, declining serum proteins present in many such patients. However, malnutrition is defined as the consequence of insufficient food or an improper diet and is generally a misdiagnosis for patients with chronic kidney disease. The mechanisms for these abnormalities are complex and have not been fully identified, but diagnosing them as malnutrition is deeply misleading since it suggests that the abnormalities can be overcome simply by supplying more food or altering the composition of the diet. To date, this approach has not proven to be successful. The investigation of dialysis patients by Pupim et al. in this issue of the JCI shows why such consequences of kidney failure result from mechanisms more complex than malnutrition (1). Their results show that a sharp increase in protein and calorie intake during dialysis produces only a transient benefit, even for end-stage renal disease (ESRD) patients with few signs of abnormal protein metabolism.

\footnotetext{
Address correspondence to: William E. Mitch, Nephrology Division, Department of Medicine, University of Texas, Galveston, 4.124 John Sealy Annex, Route 0569, 301 University Avenue, Galveston, Texas 77555, USA. Phone: (409) 772-9891; Fax: (409) 772-8562; E-mail:wmitch@utmb.edu. Conflict of interest: No conflict of interest has been declared.

Nonstandard abbreviations used: end-stage renal disease (ESRD).
}

The development of progressive kidney disease raises complex problems requiring constant attention to avoid and treat complications from lost kidney function including anemia, bone disease, abnormalities in electrolytes, and, of course, the almost universal appearance of hypertension. Worse yet, when ESRD develops, the patient is at risk of the sharp increase in mortality associated with dialysis. Crosssectional analyses of patients in dialysis units indicate that the signs and symptoms commonly attributed to malnutrition occur in $50 \%$ or more of these patients $(2,3)$.

In children with kwashiorkor or adults with severe malnutrition, many of these same abnormalities can be ameliorated when dietary protein or nitrogen is provided (4). When they occur in ESRD patients, do they also result from too little food or an improper diet? The first step in addressing this question is to determine whether some other, more fundamental abnormality arising in patients with kidney disease prevents them from utilizing dietary nutrients effectively. Normal adults characteristically respond to the restriction of dietary protein by progressively decreasing the irreversible destruction of amino acids and, consequently, the production of urea from the nitrogen of amino acids. At the limits of this adaptive response, another mechanism is activated, leading to a decrease in the degradation of protein and at least some stimulation of protein synthesis (5). These adaptive responses act to maintain protein balance, and, unless there is severe dietary restriction, they usually suffice to prevent the loss of body proteins. Fortunately, patients with uncomplicated kidney disease, including nephrotic subjects, can activate the same adaptations to dietary protein restriction and maintain protein balance and lean body mass for long periods while they are eating protein-restricted diets (6-10). However, when dialysis becomes necessary, the amounts of protein and energy required to achieve protein balance increase sharply, and it is not known if these adaptive responses occur in ESRD patients or how effective they are in preventing excessive catabolism (11).

\section{Why does ESRD mimic malnutrition?}

Studies of experimental uremia and investigations of patients with kidney failure have suggested several mechanisms that may account for the abnormalities misdiagnosed as malnutrition (Figure 1). First, metabolic acidosis is common in kidney failure and acts to stimulate the irreversible destruction of the essential, branched-chain amino acids. In addition, it accelerates the degradation of protein, especially muscle protein (12-14). The increased breakdown of muscle protein is due to activation of the ubiquitin-proteasome proteolytic system, the major system that degrades the bulk of protein in all cells, including muscle cells $(15,16)$. Recently, we obtained evidence that correcting acidosis in patients treated by chronic ambulatory peritoneal dialysis suppresses the ubiquitin-proteasome system and leads to gain of body weight (17). There also is evidence that acidosis contributes to the low level of serum albumin in dialysis patients $(18,19)$. Acidosis in kidney failure, therefore, could contribute substantially to the abnormalities presumed to be caused by malnutrition. 


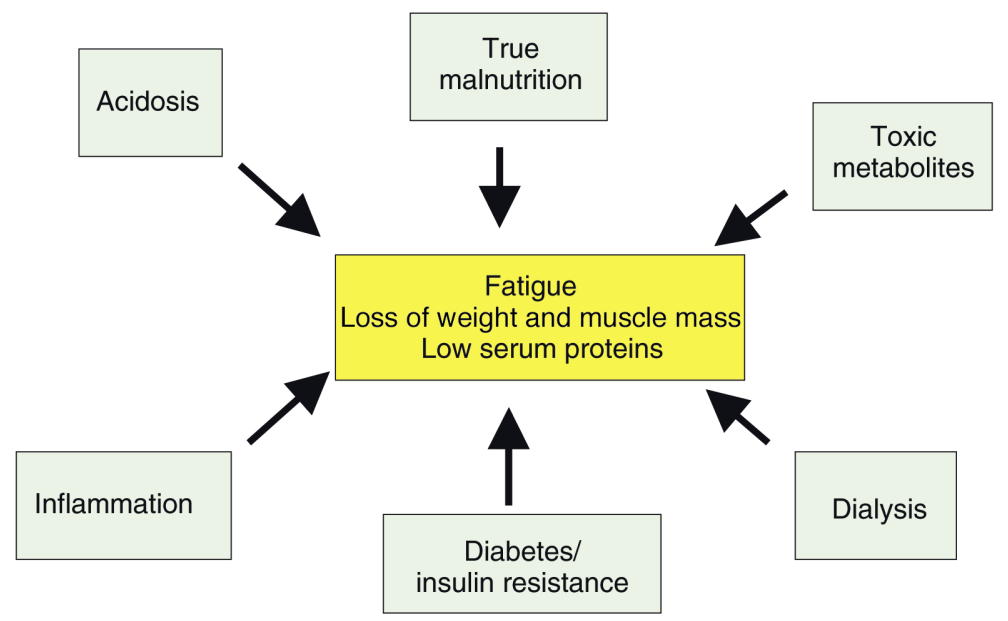

Figure 1

An inadequate diet or "true malnutrition" rarely leads to the fatigue, loss of lean body mass, and low serum proteins associated with loss of kidney function. More commonly, these problems are the result of catabolic mechanisms stimulated by renal insufficiency.

Inflammation has been touted as another cause of the problems attributed to malnutrition. In ESRD patients, circulating levels of cytokines are high $(2,20,21)$, although the sources of inflammation in these patients are not fully understood. Kaysen et al. have systematically examined the contribution of signs of inflammation (circulating acutephase reactant proteins) and dietary protein to changes in serum albumin in well-characterized hemodialysis patients $(22,23)$. They reported that high circulating levels of the longerlived acute phase proteins, such as ceruloplasmin, presage a decrease in albumin in the following month; they also concluded that inadequate amounts of dietary protein can aggravate hypoalbuminemia.

The common thread in models of inflammatory conditions that cause loss of muscle mass is activation of the ubiquitin-proteasome proteolytic system, as has been demonstrated repeatedly in models of sepsis and inflammatory conditions (16). The administration of TNF- $\alpha$ (and other cytokines) to rodents can stimulate protein degradation in muscle, but it is difficult to assign this response to the action of a single cytokine $(24,25)$. To date, cytokine-activated mechanisms that lead to accelerated muscle proteolysis by the ubiquitin-proteasome system have not been worked out fully, but, as with acidosis, the catabolic responses appear to depend on the action of glucocorticoids (14,
26-29). Results from animal models are relevant to patients with sepsis or traumatic injury because they also exhibit evidence of heightened muscle degradation through the ubiquitinproteasome system $(30,31)$.

Another cause of the constellation of problems lumped under the diagnosis of malnutrition is resistance to the anabolic action of insulin, a characteristic of inflammation, acidosis, and other conditions associated with loss of muscle mass. Experimentally, acute diabetes mellitus causes rapid loss of body weight and muscle mass due to activation of the ubiquitin-proteasome proteolytic system in muscle (32). These catabolic responses are rapidly reversed by insulin but are independent of the acidosis of acute diabetes (33). However, as in acidosis, sepsis, and even starvation, activation of accelerated muscle proteolysis by this system requires glucocorticoids $(27,33,34)$. Since diabetes is a common cause of ESRD and kidney failure-induced resistance to the hypoglycemic action of insulin, it is likely that diabetes or insulin resistance play a role in the abnormalities attributed to malnutrition (35). Although the contribution of insulin resistance has not been quantified, it is tempting to speculate that the protein catabolism occurring when patients are dialyzed against a glucose-free bath is related to a reduced stimulation of insulin release (36).

A fourth cause of abnormalities misdiagnosed as malnutrition in ESRD patients is the dialysis procedure itself.
In the 1990 s, Bergstrom and collaborators reported that contact of the blood of normal adults with dialysis membranes could stimulate muscle protein catabolism (37). Recently, Ikizler and colleagues reinvestigated these claims systematically by measuring whole-body and muscle protein turnover in stable patients dialyzed with modern dialysis membranes (38). Remarkably, they found that dialysis stimulated whole-body degradation of protein including muscle protein. Because the catabolic response persisted after completion of the dialysis procedure, the authors concluded that the dialysis procedure per se somehow causes the breakdown of protein in dialysis patients.

A final explanation for ESRD-associated abnormalities in weight, muscle mass, and serum proteins could be that the hodgepodge of accumulated wasted products and metabolic abnormalities caused by the loss of kidney function is the culprit. Again, this mechanism is not directly connected to an inadequate diet, and in fact, an excess of protein-rich foods should only increase the accumulation of waste products like phosphates, acid, and nitrogen-containing products (39). To date, there has been no cause and effect association found between the accumulation of nitrogen-containing waste products and a specific syndrome, despite intriguing investigations about links between unidentified "middle molecules" and depressed appetite (40). Overall, evidence supporting this mechanism as a cause of the problems attributed to malnutrition is substantially weaker than for other mechanisms.

\section{Ameliorating the signs and symptoms attributed to malnutrition}

In extending their careful studies of the catabolic effects of hemodialysis, Pupim et al. now provide the first comprehensive evaluation of intradialytic parenteral nutrition (1). They confirm that hemodialysis stimulates whole-body and muscle proteolysis and then evaluate how components of protein turnover can be changed by the infusion of a mixture of amino acids, dextrose, and lipids during the catabolic dialysis procedure. The infused mixture of nutrients increased plasma insulin about sixfold and 
raised muscle protein synthesis about fourfold without suppressing wholebody or muscle protein breakdown. During the infusion, the net effect was a positive protein balance in the whole body and muscle, and there were also positive balances for carbohydrates and lipids. Unfortunately, none of these beneficial responses persisted in the immediate post-dialysis period.

The authors addressed the possibility that inflammation or some of the other mechanisms shown in Figure 1 might contribute to the effects of hemodialysis or the positive changes occurring with nutrient infusion. Notably, they found that the seven nondiabetic patients participating in the study were apparently free of inflammation, had serum bicarbonate values of greater than $22 \mathrm{mM}$ and normal values of serum proteins, and were eating $0.97-1.00 \mathrm{~g}$ protein $/ \mathrm{kg}$ per day. Their carefully obtained results are consistent with the concept that stimulating insulin signaling might offset the symptoms attributed to malnutrition in dialysis patients, but this hypothesis will need to be addressed directly, probably using the rigorous techniques employed here by Pupim et al.

In summary, there are many adverse consequences of chronic kidney disease including the constellation of signs and symptoms glossed over as malnutrition. Several mechanisms causing these problems have been identified, and the mechanisms should be explored further. To determine if intradialytic parenteral nutrition will produce greater and more long-lasting benefits, there should be a long-term study including a large number of ESRD patients with inflammation, acidosis, and other disorders associated with renal disease, as well as relatively healthy subjects like those studied here.

1. Pupim, L.B., et al. 2002. Intradialytic parenteral nutrition improves protein and energy homeostasis in chronic hemodialysis patients. J. Clin. Invest. 110:483-492. doi:10.1172/JCI200215449.

2. Qureshi, A.R., et al. 1998. Factors predicting malnutrition in hemodialysis patients: a cross-sectional study. Kidney Int. 53:773-782.

3. Bergstrom, J., et al. 2000. What are the causes and consequences of the chronic inflammatory state in chronic hemodialysis patients? Semin. Dial. 13:163-176.
4. Tripathy, K., Klahr, S., and Lotero, H. 1970. Utilization of exogenous urea nitrogen in malnourished adults. Metabolism. 19:253-262.

5. Motil, K.J., et al. 1981. Whole-body leucine and lysine metabolism: response to dietary protein intake in young men. Am. J. Physiol. 240:E712-E721.

6. Goodship, T.H.J., et al. 1990. Adaptation to lowprotein diets in renal failure: leucine turnover and nitrogen balance. J. Am. Soc. Nephrol. 1:66-75.

7. Tom, K., et al. 1995. Long-term adaptive responses to dietary protein restriction in chronic renal failure. Am. J. Physiol. 268:E668-E677.

8. Maroni, B.J., Staffeld, C., Young, V.R., Manatunga, A., and Tom, K. 1997. Mechanisms permitting nephrotic patients to achieve nitrogen equilibrium with a protein-restricted diet. J. Clin. Invest. 99:2479-2487.

9. Walser, M., and Hill, S. 1999. Can renal replacement be deferred by a supplemented very-low protein diet? J. Am. Soc. Nephrol. 10:110-116.

10. Aparicio, M., et al. 2000. Nutrition and outcome on renal replacement therapy of patients with chronic renal failure treated by a supplemented very low protein diet. J. Am. Soc. Nephrol. 11:719-727.

11. Mitch, W.E. 2002. Requirements for protein, calories, and fat in the predialysis patient. In Handbook of nutrition and the kidney. W.E. Mitch and S. Klahr, editors. Lippincott, Williams and Wilkins. Philadelphia, Pennsylvania, USA. 144-165.

12. Hara, Y., May, R.C., Kelly, R.A., and Mitch, W.E. 1987. Acidosis, not azotemia, stimulates branched-chain amino acid catabolism in uremic rats. Kidney Int. 32:808-814.

13. May, R.C., Kelly, R.A., and Mitch, W.E. 1987. Mechanisms for defects in muscle protein metabolism in rats with chronic uremia: the influence of metabolic acidosis. J. Clin. Invest. 79:1099-1103.

14. May, R.C., Bailey, J.L., Mitch, W.E., Masud, T. and England, B.K. 1996. Glucocorticoids and acidosis stimulate protein and amino acid catabolism in vivo. Kidney Int. 49:679-683.

15. Bailey, J.L., et al. 1996. The acidosis of chronic renal failure activates muscle proteolysis in rats by augmenting transcription of genes encoding proteins of the ATP-dependent, ubiquitin-proteasome pathway. J. Clin. Invest. 97:1447-1453.

16. Mitch, W.E., and Goldberg, A.L. 1996. Mechanisms of muscle wasting: the role of the ubiquitin-proteasome system. N. Engl. J. Med. 335:1897-1905

17. Pickering, W.P., et al. 2002. Nutrition in CAPD: serum bicarbonate and the ubiquitin-proteasome system in muscle. Kidney Int. 61:1286-1292.

18. Ballmer, P.E., et al. 1995. Chronic metabolic acidosis decreases albumin synthesis and induces negative nitrogen balance in humans. J. Clin. Invest. 95:39-45.

19. Movilli, E., et al. 1998. Correction of metabolic acidosis increases serum albumin concentration and decreases kinetically evaluated protein intake in hemodialysis patients: a prospective study. Nephrol. Dial. Transplant. 13:1719-1722.

20. Pereira, B.J., et al. 1994. Plasma levels of IL-1 $\beta$, TNF- $\alpha$ and their specific inhibitors in undialyzed chronic renal failure, CAPD, and hemodialysis patients. Kidney Int. 45:890-896.

21. Nassar, G.M., and Ayus, J.C. 2001. Infectious complications of the dialysis access. Kidney Int. 60:1-13.

22. Kaysen, G.A., Dubin, A., Muller, H.G., Mitch, W.E., and Levin, N.W. 2001. Levels of $\alpha-1$ acid glycoprotein and ceruloplasmin predict future albumin levels in hemodialysis patients. Kidney Int. 60:2360-2366.

23. Kaysen, G.A. 1998. Biological basis of hypoalbuminemia in ESRD. J. Am. Soc. Nephrol. 9:2368-2376.

24. Goodman, M.N. 1991. Tumor necrosis factor induces skeletal muscle protein breakdown in rats. Am. J. Physiol. 260:E727-E730.

25. Goldberg, A.L., Kettlehut, I.C., Furuno, K. Fagan, J.M., and Baracos, V. 1988. Activation of protein breakdown and prostaglandin E2 production in rat skeletal muscle in fever is signaled by a macrophage product distinct from interleukin 1 or other known monokines. J. Clin. Invest. 81:1378-1383.

26. Price, S.R., England, B.K., Bailey, J.L., Van Vreede, K., and Mitch, W.E. 1994. Acidosis and glucocorticoids concomitantly increase ubiquitin and proteasome subunit mRNAs in rat muscle. Am. J. Physiol. 267:C955-C960.

27. Tiao, G., et al. 1996. Energy-ubiquitin-dependent muscle proteolysis during sepsis in rats is regulated by glucocorticoids. J. Clin. Invest. 97:339-348.

28. Du, J., Mitch, W.E., Wang, X., and Price, S.R. 2000. Glucocorticoids induce proteasome C3 subunit expression in L6 muscle cells by opposing the suppression of its transcription by NF-kB. J. Biol. Chem. 275:19661-19666.

29. Mitch, W.E., and Price, S.R. 2001. Transcription factors and muscle cachexia: have we defined a therapeutic target? Lancet. 357:734-735.

30. Tiao, G., et al. 1997. Sepsis is associated with increased mRNAs of the ubiquitin-proteasome proteolytic pathway in human skeletal muscle. J. Clin. Invest. 99:163-168.

31. Mansoor, O., et al. 1996. Increased mRNA levels for components of the lysosomal, $\mathrm{Ca}^{++-a c t i v a t}$ ed and ATP-ubiquitin-dependent proteolytic pathways in skeletal muscle from head trauma patients. Proc. Natl. Acad. Sci. USA. 93:2714-2718.

32. Price, S.R., et al. 1996. Muscle wasting in insulinopenic rats results from activation of the ATP-dependent, ubiquitin-proteasome pathway by a mechanism including gene transcription. J. Clin. Invest. 98:1703-1708.

33. Mitch, W.E., et al. 1999. Evaluation of signals activating ubiquitin-proteasome proteolysis in a model of muscle wasting. Am. J. Physiol. 276:C1132-C1138.

34. Wing, S.S., and Goldberg, A.L. 1993. Glucocorticoids activate the ATP-ubiquitin-dependent proteolytic system in skeletal muscle during fasting. Am. J. Physiol. 264:E668-E676.

35. DeFronzo, R.A., Tobin, J.D., Rowe, J.W., and Andres, R. 1978. Glucose intolerance in uremia. J. Clin. Invest. 62:425-430.

36. Gutierrez, A., Bergstrom, J., and Alvestrand, A. 1994. Hemodialysis-associated protein catabolism with and without glucose in the dialysis fluid. Kidney Int. 46:814-822.

37. Guiterrez, A., Alvestrand, A., Wahren, J., and Bergstrom, J. 1990. Effect of in vivo contact between blood and dialysis membranes on protein catabolism in humans. Kidney Int. 38:487-494.

38. Ikizler, T.A., et al. 2002. Hemodialysis stimulates muscle and whole body protein loss and alters substrate oxidation. Am. J. Physiol. 282:E107-E116.

39. Hakim, R.M., and Lazarus, J.M. 1988. Biochemical parameters in chronic renal failure. Am. J. Kid ney Dis. 9:238-247.

40. Anderstam, B., Mamoun, A.-H., Bergstrom, J., and Sodersten, P. 1996. Middle-sized molecule fractions isolated from uremic ultrafiltrate and normal urine inhibit ingestive behavior in the rat. J. Am. Soc. Nephrol. 7:2453-2460. 